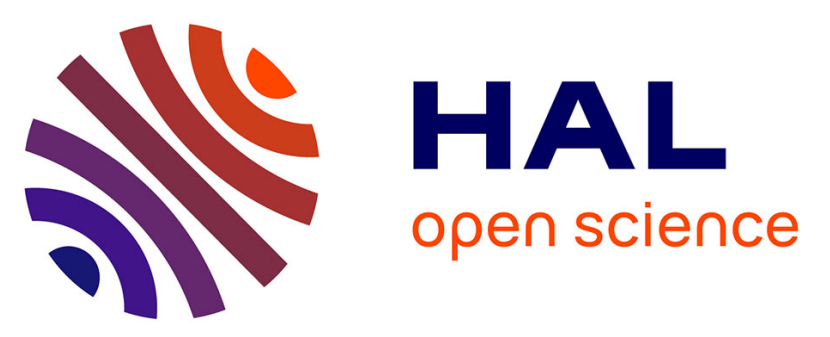

\title{
Phytoavailability of silver at predicted environmental concentrations: does the initial ionic or nanoparticulate form matter?
}

\author{
C. Layet, Catherine Santaella, M. Auffan, C. Chevassus-Rosset, M. Montes, \\ C. Levard, P. Ortet, M. Barakat, E. Doelsch
}

\section{To cite this version:}

C. Layet, Catherine Santaella, M. Auffan, C. Chevassus-Rosset, M. Montes, et al.. Phytoavailability of silver at predicted environmental concentrations: does the initial ionic or nanoparticulate form matter?. Environmental science.Nano, 2019, 6 (1), pp.127-135. 10.1039/c8en00644j . hal-01924712

\section{HAL Id: hal-01924712 \\ https://hal-amu.archives-ouvertes.fr/hal-01924712}

Submitted on 5 Mar 2019

HAL is a multi-disciplinary open access archive for the deposit and dissemination of scientific research documents, whether they are published or not. The documents may come from teaching and research institutions in France or abroad, or from public or private research centers.
L'archive ouverte pluridisciplinaire HAL, est destinée au dépôt et à la diffusion de documents scientifiques de niveau recherche, publiés ou non, émanant des établissements d'enseignement et de recherche français ou étrangers, des laboratoires publics ou privés. 


\section{Environmental Science Nano}

Check for updates

Cite this: DOI: $10.1039 / \mathrm{c} 8 \mathrm{en} 00644 \mathrm{j}$

Received 14th June 2018,

Accepted 3rd October 2018

DOI: $10.1039 / c 8 e n 00644 j$

rsc.li/es-nano

\section{Phytoavailability of silver at predicted environmental concentrations: does the initial ionic or nanoparticulate form matter? $\dagger$}

\author{
C. Layet, ${ }^{\text {ab }}$ C. Santaella, iD bcd M. Auffan, iD abe C. Chevassus-Rosset, ${ }^{\text {fg }}$ M. Montes, ${ }^{\text {fg }}$ \\ C. Levard, iD ${ }^{\text {ab }}$ P. Ortet, ${ }^{c d}$ M. Barakat ${ }^{c d}$ and E. Doelsch (iD *fg
}

\begin{abstract}
Silver phytoavailability in exposure scenarios close to predicted environmental concentrations (PEC) has rarely been studied. The ISO-standardized RHIZOtest, based on a root mat technique, was used to expose tall fescue (Festuca arundinacea) to silver at a concentration close to $0.0015 \mathrm{mg} \mathrm{kg}^{-1}$ and 100 times higher $\left(0.15 \mathrm{mg} \mathrm{kg}^{-1}\right.$ ) than PEC in soils (the PEC of Ag nanoparticulate in the soil range from $6 \times 10^{-6}$ to $1.4 \times 10^{-3}$ $\mathrm{mg} \mathrm{kg}^{-1}$ ). Silver was supplied in the form of nanoparticles with organic (PVP) or inorganic $\left(\mathrm{SiO}_{2}\right)$ coating, or as dissolved $\mathrm{Ag}\left(\mathrm{AgNO}_{3}\right)$, in different soil types, with contrasting properties, including $\mathrm{pH}$, cationic exchange capacity, and carbonate, organic matter, and clay contents. The Ag concentration was quantified in plant roots and leaves and in soil solutions using ICP-MS spectrometry. Multivariate analyses showed that the form of Ag, nanoparticulate or ionic, had no impact on either the flux or the translocation of $\mathrm{Ag}$ in plants ( $p$-value > 0.05). At a silver concentration close to PEC, Ag phytoavailability from $\mathrm{Ag} \mathrm{NPs} \mathrm{or} \mathrm{AgNO}_{3}$ was indistinguishable from that of geogenic Ag. At 100× PEC, the type of soil, mainly clay and carbonate contents, controlled the Ag flux. While both decreased Ag in soil solution, clays and carbonates showed antagonistic actions in modulating the Ag flux. We hypothesize that proton root exudation locally dissolves carbonates and releases phytoavailable Ag, while immobilizing Ag on the edges of clays.
\end{abstract}

\section{Environmental significance}

Silver nanoparticles are predicted to be released into soils at concentrations ranging from $\mathrm{ng} \mathrm{kg}^{-1}$ to $\mu \mathrm{g} \mathrm{kg}^{-1}$ but their phytoavailability at such low concentrations remains unknown. Here, we used the ISO-standardized RHIZOtest to understand how the form of silver (ionic or nanoparticulate with (in) organic coatings) and soil properties regulate silver phytoavailability in the range of predicted environmental concentrations. At the lowest concentration tested, the silver phytoavailability induced by nanoparticle or ionic forms was indistinguishable from that of the control. At higher silver concentrations, soil properties controlled silver phytoavailability, whereas no difference was observed between the forms of silver. These findings demonstrate that realistic exposure scenarios need to be used to enable robust environmental risk assessments.

\section{Introduction}

The inhibitory and antimicrobial properties of silver have been known for centuries. Silver nanomaterials (Ag NMs)

\footnotetext{
${ }^{a}$ Aix Marseille Univ, CNRS, IRD, INRA, Coll France, CEREGE, Aix-en-Provence, France

${ }^{b}$ iCEINT, International Center for the Environmental Implications of

NanoTechologies, 13545 Aix-en-Provence, France

${ }^{c}$ Aix Marseille Univ, CEA, CNRS, Laboratory for Microbial Ecology of the Rhizosphere and Extreme Environments (LEMIRE), UMR7265 BIAM, F-13108 Saint-Paul-lez-Durance, France

${ }^{d}$ Aix Marseille Univ, CNRS, FR 3098 ECCOREV, F-13545 Aix-en-Provence, France

${ }^{e}$ Duke University, Civil and Environmental Engineering, Durham, USA

${ }^{f}$ CIRAD, UPR Recyclage et risque, F-34398 Montpellier, France.

E-mail: doelsch@cirad.fr

${ }^{g}$ Recyclage et Risque, Univ Montpellier, CIRAD, Montpellier, France

$\dagger$ Electronic supplementary information (ESI) available: Silver K-edge XANES spectra, isoelectric points, principal component analysis of the dataset, and soil characteristics. See DOI: 10.1039/c8en00644j
}

have been a part of our daily lives in the past few years ${ }^{1}$ due to their antimicrobial properties. ${ }^{2}$ Their success in applications including human health, surface coatings, food packaging, and textiles is due to the effective silver concentrations required for antimicrobial properties that are lower at the nanoscale than bulk materials and in some cases ionic $\mathrm{Ag}^{3}{ }^{3}$

Based on the life-cycle of Ag NM-enabled products, the main release pattern of $\mathrm{Ag}$ NMs into the environment is through wastewater treatment plants and sludge spreading in agricultural soils as fertilizer. ${ }^{4}$ Other unquantified sources of $\mathrm{Ag}$ NMs are pesticides where they are used against plant pathogens and insect pests, ${ }^{5}$ and deposits from incineration fumes. ${ }^{6}$ The predicted environmental concentrations (PEC) of Ag NMs in the soil range from 6 to $21 \mathrm{ng} \mathrm{kg}^{-1}$ in agricultural soils and 50-530 $\mathrm{ng} \mathrm{\textrm {kg } ^ { - 1 }}$ in sludge-treated soils in Denmark. ${ }^{4}$ Using dynamic probabilistic modelling, Sun et al. $(2014)^{7}$ estimated the PEC of 
$\mathrm{Ag}$ NMs in the EU to range from 30 to $80 \mathrm{ng} \mathrm{kg}^{-1}$ in natural and urban soils and from 1290 to $1390 \mathrm{ng} \mathrm{kg}^{-1}$ in sludgetreated soils by 2020 . In soils, porous waters, sludge, etc., Ag NMs are known to be physically and chemically unstable. They quickly undergo physical-chemical transformations (oxidation, sulfidation, dissolution, and adsorption/complexation with natural colloids) thereby altering their properties, mobility, fate and interactions with living organisms. ${ }^{8}$

In realistic release scenarios, $\mathrm{Ag}$ NMs are expected to reach plant crops. Several studies have already assessed the phytotoxicity and phytoavailability of Ag NMs. However, most of them were hydroponic studies. Ag NMs were found to alter seed germination, plant biomass, and plant physiology, and to generate oxidative stress. The non-exhaustive list of factors governing Ag NM phytotoxicity included the size, shape, and coating of the NMs, the plant genotype, and the experimental methods. ${ }^{9}$ Plant roots were considered as the main route of $\mathrm{Ag}$ NM entry into plants with subsequent translocation to the shoots and leaves. ${ }^{10-12}$ Stegemeier et al. $(2015)^{13}$ studied the uptake and distribution of silver in alfalfa (Medicago sativa) exposed to pristine $\mathrm{Ag} \mathrm{NMs}$, sulfidized $\mathrm{Ag}_{2} \mathrm{~S}$ NMs and ionic $\mathrm{Ag}$ at $3 \mathrm{mg} \mathrm{L}^{-1}$ in hydroponics. Despite marked differences in the release of $\mathrm{Ag}^{+}$ions from the nanoparticles, $\mathrm{Ag} \mathrm{NMs}, \mathrm{Ag}_{2} \mathrm{~S}$ $\mathrm{NMs}$, and $\mathrm{Ag}^{+}$showed similar quantitative patterns of association with plant roots and similarly limited $(<1 \%)$ translocation of Ag to shoots. However, the local distribution of silver in plant roots was $\mathrm{Ag}$ speciation-dependent. Exposing wheat plants to $\mathrm{Ag} \mathrm{NMs}, \mathrm{Ag}_{2} \mathrm{~S}$ NMs and ionic $\mathrm{Ag}\left(3 \mathrm{mg} \mathrm{L}^{-1}\right)$ in hydroponics, Pradas del Real et al. $(2017)^{14}$ showed that various chemical transformations occurred in plant roots, leading to the dynamic exposure of the plant to multiple forms of silver.

The interactions between NMs and mineral phases, natural organic matter, and microbiota ${ }^{15}$ have to be taken into account when studying Ag phytoavailability and phytotoxicity in the soil. ${ }^{16,17}$ Dimkpa et al. $(2013)^{18}$ exposed wheat to Ag NMs in a sand matrix (0.5-2.5 $\mathrm{mg} \mathrm{\textrm {kg } ^ { - 1 }}$ ) and observed a dosedependent reduction in growth. Pradas del Real et al. $(2016)^{19}$ spread Ag NM-amended sludge (18 and $400 \mathrm{mg} \mathrm{kg}^{-1}$ ) on soil and detected $\mathrm{Ag}$ in the rhizosphere of wheat and rape, as nanosized $\mathrm{Ag}_{2} \mathrm{~S}, \mathrm{Ag}-\mathrm{S}$ species and mixed metallic sulfides with $\mathrm{Zn}$ and $\mathrm{Cu}$. Following such exposure, Ag was undetectable in the soil pore water and poorly accumulated in plant shoots. Doolette et al. $(2015)^{20}$ studied the bioavailability of $\mathrm{Ag}$ in lettuce using a sandy soil amended with biosolids containing $\mathrm{Ag}_{2} \mathrm{~S}$ NMs and reported limited accumulation in shoots. $\mathrm{Ag}_{2} \mathrm{~S}$ NMs applied directly to a sandy soil at $1 \mathrm{mg} \mathrm{kg}^{-1}$ were less bioavailable than $\mathrm{Ag}_{2} \mathrm{~S}$ NM-containing biosolids. In an outdoor lysimeter study, Schlich et al. $(2017)^{21}$ exposed canola and wheat to $\mathrm{Ag}$ NMs (1.7 and $8.0 \mathrm{mg} \mathrm{kg}^{-1}$ ) via sewage sludge in a loamy-sand soil. Despite low remobilization of $\mathrm{Ag}$ from the soil to the percolating water, $\mathrm{Ag}$ uptake by roots showed that the chemical conditions in the rhizosphere induced $\mathrm{Ag}$ remobilization from the incorporated sewage sludge.

Several studies have deciphered the interactions between soil properties and $\mathrm{Ag} \mathrm{NMs}^{22,23}$ but only a few studies have addressed the silver phytoavailability at PEC. The aim of the present study was to evaluate the impact of soil properties on Ag phytoavailability in tall fescue (Festuca arundinacea), using a set of soils with contrasting properties (clay, organic and carbonate contents, cationic exchange capacity, $\mathrm{pH}$, etc.). We also studied the role of the form of silver using nanoparticulate $\mathrm{Ag}$ with inorganic $\left(\mathrm{SiO}_{2}\right)$ and organic (polyvinylpyrrolidone, PVP) coatings, and dissolved $\mathrm{Ag}\left(\mathrm{AgNO}_{3}\right)$ as silver sources. To study Ag soil-plant transfers, we used a RHIZOtest device, ${ }^{24}$ which is based on a root mat placed in close contact with the soil. This technique allows easy and rapid harvesting of the whole plant and the soil. Recently, the RHIZOtest was shown to be a useful tool to analyze the phytoavailability of $\mathrm{CeO}_{2} \mathrm{NMs}$ at concentrations close to PEC in fescue and tomato. ${ }^{16}$ Here, we selected two concentrations lower than the ones already published in studies dealing with the phytoavailability of Ag NMs in soils i.e. close to Ag PEC in soils (0.0015 $\left.\mathrm{mg} \mathrm{kg}^{-1}\right)$ and 100 times higher than PEC $\left(0.15 \mathrm{mg} \mathrm{kg}^{-1}\right)$.

\section{Materials and methods}

\section{$\mathrm{Ag}$ nanoparticles and dissolved $\mathrm{Ag}$}

Two Ag nanoparticles of similar size (TEM core diameter $\sim 50$ $\mathrm{nm}$ ) and shape (spherical) but with different coatings (PVP and $\mathrm{SiO}_{2}$ ) with the trade names ' $50 \mathrm{~nm}$ PVP Nanoxact" ver' and ' $50 \mathrm{~nm}$ silica coated Nanoxact ${ }^{\mathrm{TM}}$ Silver' were obtained from nanoComposix (San Diego, CA). Dissolved silver was obtained from $\mathrm{AgNO}_{3}$ (Sigma-Aldrich, Saint Louis, MI) dissolved in Milli-Q water. In the commercial stock suspensions, $\mathrm{SiO}_{2}$-AgNPs were suspended in isopropyl alcohol at $1000 \mathrm{mg} \mathrm{Ag} \mathrm{L}^{-1}$ and PVP-AgNPs in Milli-Q water at $20 \mathrm{mg} \mathrm{Ag}$ $\mathrm{L}^{-1}$. These stock suspensions were diluted in Milli-Q water (4.5 $\mathrm{mg} \mathrm{Ag} \mathrm{L}^{-1}$ and $45 \mathrm{mg} \mathrm{Ag} \mathrm{L}^{-1}$ ) before soil contamination and characterized by transmission electron microscopy (JEOL JEM 2011), X-ray absorption spectroscopy (at the Ag K-edge on the BM30b FAME beamline, ESRF, Grenoble, France), dynamic light scattering (Nano ZS, Malvern, UK), and zeta potential measurements (Zetasizer, Malvern, UK).

After dilution in Milli-Q water, the $\mathrm{SiO}_{2^{-}}$and PVP-AgNPs contained crystallites of metallic silver (see ESI $\dagger$ Fig. S1, XANES Ag K edge), with a bimodal TEM size distribution with two populations centered at $\sim 50 \mathrm{~nm}$ and $\sim 5 \mathrm{~nm}$ (Fig. 1). The population at $50 \mathrm{~nm}$ matched the size provided by the supplier. According to the TEM observation, the population at $\sim 5 \mathrm{~nm}$ was likely attributed to the dissolution/re-precipitation of silver due to changes in chemical equilibrium as a result of dilution (Fig. 1). Respectively, $2 \%$ and $6.5 \%$ of the total silver is in the ionic form in the diluted PVP-AgNP and $\mathrm{SiO}_{2}$-AgNP suspensions as measured by ICP-MS following ultra-filtration (Amicon tubes, $3 \mathrm{kDa}$ ). The TEM pictures also revealed that the thickness of the $\mathrm{SiO}_{2}$ coating around the $\mathrm{Ag}$ core was heterogeneous (varying between 10 and $30 \mathrm{~nm}$ ). The zeta potentials of the PVP-AgNPs were negative ( $-11 \pm 2 \mathrm{mV}$ in Milli-Q water) between pH 2 and 6 due to the negatively-charged PVP coating ${ }^{25}$ (see ESI $\uparrow$ Fig. S2). However, for the $\mathrm{SiO}_{2}$-AgNPs, a positive/negative inversion of the zeta potential occurred around $\mathrm{pH} 4$, attributed to the $\mathrm{SiO}_{2}$ coating ${ }^{26}$ (see ESI† Fig. S2). 


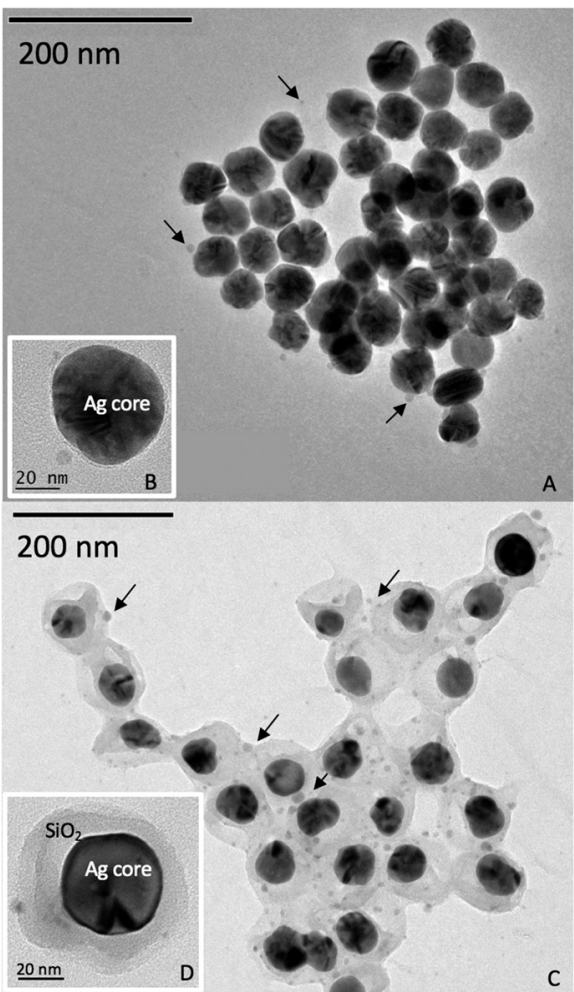

Fig. 1 Transmission electron microscopy of the PVP-AgNPs (A and B) and $\mathrm{SiO}_{2}$-AgNPs (C and D) diluted in Milli- $Q$ water. The arrows indicate the presence of small nanoparticles attributed to dissolution/re-precipitation during dilution.

\section{Soil characteristics and treatments}

Four soils with different $\mathrm{pH}$ values, organic matter and carbonate contents, cation exchange capacities (CEC) and particle size distributions were selected (Fig. 2 and ESI $\uparrow$ Table S1). Clay and sandy loam were purchased from LUFA Speyer and were classified (WRB) as a vertisol coming from Hanhofen (Germany) and as a gleysol from Siebeldingen (Germany). The loam with high OM content was a luvisol sampled in a field under permanent pasture (Cote Saint-André, France) and the loam with high carbonate content was a rendosol sampled in a field that had not been cultivated for more than 10 years (Collias, France).

The soils were treated with PVP-AgNP and $\mathrm{SiO}_{2}$-AgNP suspensions and dissolved silver solution with 0.0015 and 0.15 $\mathrm{mg}$ of Ag per $\mathrm{kg}$ of soil (dry mass). The lowest concentration was selected based on the range of PEC estimated. ${ }^{7}$

\section{RHIZOtest experiment}

The experimental procedure is detailed elsewhere. ${ }^{16,24}$ The RHIZOtest is a two-step procedure. The plant seedlings were first grown (preculture period) for 14 days in hydroponics in a cylinder closed at the bottom with a $30 \mu \mathrm{m}$ polyamide mesh to promote the development of a dense, planar root mat. In the second step (culture period), the plants were pressed down firmly onto a $6 \mathrm{~mm}$-thick layer of soil for a period of eight days. Immediately preceding the contact between the plant

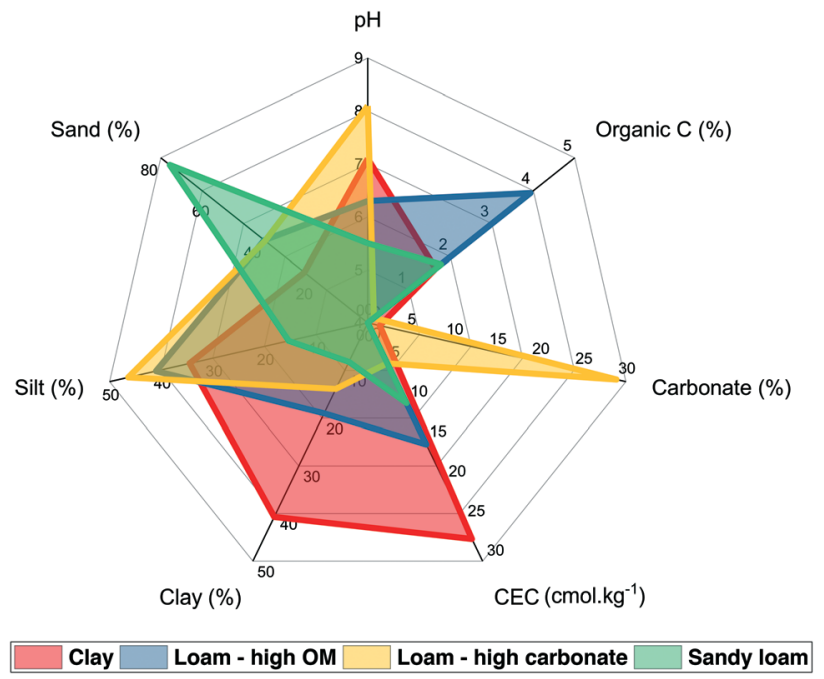

Fig. 2 Soil characteristics.

and soil, $300 \mu \mathrm{L}$ of silver (in either the nanoparticulate or dissolved form) were added to the soil surface. Five replicates were performed for each condition (silver treatment $\times$ silver concentration $\times$ soil type) and control (no $\mathrm{Ag}$ added), representing a total of 140 plant pots. The whole RHIZOtest experiment was conducted in a growth chamber under controlled climatic conditions ( $16 \mathrm{~h}$ day, $200-400 \mu \mathrm{mol}$ of photons $\mathrm{m}^{-2} \mathrm{~s}^{-1}, 75 \%$ relative humidity and a temperature of $25^{\circ} \mathrm{C} ; 8 \mathrm{~h}$ night, $70 \%$ relative humidity and a temperature of $20^{\circ} \mathrm{C}$ ).

At the end of the culture period, shoots have been separated from roots by cutting and both parts were dried at $\mathbf{5 0}$ ${ }^{\circ} \mathrm{C}$ to measure their biomass. The plant samples were then burned for two hours in a platinum cup at $500{ }^{\circ} \mathrm{C}$. The ashes were mixed with a few drops of pure water and $2 \mathrm{~mL}$ of nitric acid $\left(6 \mathrm{~mol} \mathrm{~L}^{-1}\right)$ and the solutions were filtered using ashless filter paper in a volumetric flask. The filters containing the residues were burned for $30 \mathrm{~min}$ at $500{ }^{\circ} \mathrm{C}$, moistened with a few drops of ultra-pure water, mixed with $2 \mathrm{~mL}$ of concentrated hydrofluoric acid and boiled on a hot plate until evaporation. The residues were mixed with a few drops of pure water and $2 \mathrm{~mL}$ of nitric acid $\left(6 \mathrm{~mol} \mathrm{~L}^{-1}\right)$, and the solutions were transferred to the same volumetric flasks, which were topped up to the gauge level with ultra-pure water. A set of control plants was harvested at the end of the preculture period in hydroponics to determine the pool of silver in the plants before exposure to soil.

\section{Ag concentrations and fluxes in plants}

The total silver concentrations were determined with an inductively coupled plasma-mass spectrometer (Thermo Scientific iCAP Q ICP-MS using the kinetic energy discrimination mode and $\mathrm{He}$ as the collision gas). An internal solution containing Be, Sc, Ge, Ir and Rh was added on-line to the samples to correct signal drifts. A calibration curve including 4 points $(0,1,5$ and $10 \mathrm{ppb})$ was analyzed every $20-30$ samples. For quality control, in-house reference samples and 
certified samples were used every 20 samples and each analysis was conducted in triplicate. The detection and quantification limits were $0.01 \mu \mathrm{g} \mathrm{L}^{-1}$ and $0.033 \mu \mathrm{g} \mathrm{L}^{-1}$. The measurement uncertainty was $10 \%$. The flux (ng m $\mathrm{m}^{-2} \mathrm{~s}^{-1}$ ) of silver taken up in whole plants (roots and shoots pooled together) during the test culture period can be calculated according to eqn (1):

$$
F=\frac{\left[\left(C_{\mathrm{f}} \times m_{\mathrm{f}}\right)-\left(C_{\mathrm{p}} \times m_{\mathrm{p}}\right)\right]}{S \times t}
$$

where $C_{\mathrm{f}}$ is the concentration of silver in the plant at the end of the test culture period;

$m_{\mathrm{f}}$ is the dry biomass of the plant at the end of the test culture period;

$C_{\mathrm{p}}$ is the concentration of silver in the control plant pot at the end of the preculture period;

$m_{\mathrm{p}}$ is the mean dry biomass of roots in the control plant pot at the end of the preculture period;

$S$ is the surface area of the root mat in contact with the soil; $t$ is the duration of the test culture period.

\section{Analysis of the soil solutions}

At plant harvest, the soil in each plant pot was collected. A surrogate of soil solution was recovered by soil extraction (soil: water ratio $1: 10$ ) with the nutrient solution. The mixture was shaken for $45 \mathrm{~min}$ in a rotary shaker at $16 \mathrm{rpm}$ and centrifuged for $20 \mathrm{~min}$ at $4000 \mathrm{~g}$. The soil solution samples were split into three aliquots. The first untreated and unfiltered aliquot was used for $\mathrm{pH}$ analyses. The remaining aliquots were filtered through a $0.45 \mu \mathrm{m}$ polyethersulfone membrane filter. The second aliquot was acidified with nitric acid (65\%, for trace analysis, Sigma Aldrich) to quantify the concentration of silver in the soil solution using ICP-MS spectrometry. The third aliquot was mixed with $10 \mu \mathrm{L}$ sodium azide (final concentration of $1 \times 10^{-3} \mathrm{~mol} \mathrm{~L}^{-1}$ in the aliquot) and used to quantify dissolved organic carbon content (TOC-L $\mathrm{CSH}$, Shimadzu). The last two aliquots were stored at $4^{\circ} \mathrm{C}$ before analysis.

\section{Statistics}

The distribution of the investigated variables and residues was tested for normality using the Shapiro-Wilk test and for homoscedasticity using Levene's test. Grubbs' test and median absolute deviation were used to identify outliers.

Principal component analysis (PCA) was used to describe the data set and to reduce the dimensionality by projecting each sample onto the main principal components. ${ }^{27}$ PCA was performed on 102 observations, each corresponding to an individual RHIZOtest experiment. The environmental variables (levels) were the soil type (clay, loam with high OM content, sandy loam, and loam with high carbonate content), treatment $\left(\mathrm{AgNO}_{3}, \mathrm{PVP}-\mathrm{AgNPs}, \mathrm{SiO}_{2}\right.$-AgNPs and controls), and the exposure concentration of silver $\left(0,0.0015\right.$, and $\left.0.15 \mathrm{mg} \mathrm{kg}^{-1}\right)$. The response variables were $\mathrm{Ag}$ flux, $\mathrm{pH}$, DOC and $\mathrm{Ag}$ concentration in the soil solution and in the plant mass (roots and leaves). As the response variables were not dimensionally homogeneous, they were centered and scaled to unit variance. Analyses were carried out in the statistical environment $\mathrm{R}^{28}$ using the ade4 (ref. 29) and adegraphics packages. ${ }^{30}$

PCA was completed by redundancy canonical analysis (RDA) to study the relationships between the response variables and the environmental variables. The quantitative environmental variables concerned the soil parameters, i.e. the cationic exchange concentration (CEC), the percentage of clay and organic matter, the $\mathrm{pH}$, the carbonate concentration, and the exposure concentration of silver used. The non-quantitative environmental variable was the treatment (the same as those used in the PCA). The RDA was implemented in XLSTAT 2015.6.

Differences among groups with multiple response variables were assessed using permutation-based multivariate analysis of variance (PERMANOVA, 1000 permutations) in Vegan. ${ }^{31}$

As the Ag flux fits a non-normal distribution, we used the non-parametric Kruskal-Wallis test followed by Dunn's post hoc test in the $\mathrm{R}$ environment ${ }^{28}$ to compare the $\mathrm{Ag}$ flux among the treatment groups. The $p$-values were corrected for false discovery rates due to multiple post hoc comparisons using the Benjamini-Hochberg (BH) method. ${ }^{32} p$-Values or BH-corrected Dunn's post hoc test $p$-values under 0.05 were considered to be statistically significant.

Simple regression was implemented in StatGraphics Centurion XVI.II and XLSTAT to describe the relationships between the outcome variable Ag flux and the predictor variable $\mathrm{Ag}$ concentration applied or in soil solution among the treatment groups. The lack-of-fit test was used to assess whether the selected model adequately described the observed data. The Durbin-Watson statistic tested the residuals to determine any significant autocorrelation based on the order in which they occur in the data file.

\section{Results and discussion}

\section{Soil type-dependent Ag phytoavailability at PEC and 100 $\times$ PEC}

Principal component analysis (PCA) was used to detect patterns in the dataset and to describe linear relations between the response variables ( $\mathrm{Ag}$ flux, plant mass, $\mathrm{pH}, \mathrm{DOC}$ and the concentration of $\mathrm{Ag}$ in the soil solution). The three first components (PC1, PC2, and PC3) accounted for $77.7 \%$ of the variability. The score plots showed clustering based on the soil type on the first component (see ESI $\dagger$ Fig. S3). The correlation loading plots (ESI $\uparrow$ Fig. S3) indicated no significant correlation between the $\mathrm{Ag}$ flux and the other variables $(\mathrm{pH}$ and DOC in soil solution and biomass).

To test the simultaneous responses of the $\mathrm{Ag}$ flux variable to the environmental variables (soil characteristics, Ag treatments and concentrations), a permutation-based method (PERMANOVA) was used which requires the independence of the variables but not their normal distribution. According to the pseudo-Fisher ratio $(F)$ and the $p$-values, the PERMANOVA revealed a highly significant effect of the Ag exposure concentration $(F=90.2, p$-value $<0.001)$, the soil type $(F=15.0, p$-value $<0.001)$ and the treatment $(F=7.1, p$-value 
$<0.001$ ) on the Ag flux. When the values of the control (no $\mathrm{Ag}$ added) were removed from the data set, the treatment no longer had an impact on the $\mathrm{Ag}$ flux variable ( $p$-value $>$ 0.05), showing that the phytoavailability of silver was basically the same under AgNP (PVP and $\mathrm{SiO}_{2}$-coated) and $\mathrm{AgNO}_{3}$ treatments.

As none of the response variables were correlated, redundancy analysis (RDA) was used to describe the response variables (Ag flux, plant mass, $\mathrm{pH}$, DOC and $\mathrm{Ag}$ concentration in soil solution) with the set of environmental variables (soil characteristics (see ESI $\dagger$ Table S1), Ag treatments and concentration), used as explanatory variables. The results of the RDA are shown in Fig. 3. The angle between the response variables (black arrows) or between the environmental variables (red arrows) indicates the degree of linear correlation between them. The right-angled projection of centroid points (blue circles), indicating non-quantitative variables, onto a response variable (black arrows) approximates the relationship between these variables. The constrained part of the RDA explained $57.8 \%$ of the total variability. The first (F1) and second (F2) components accounted for $55.3 \%$ and $29.2 \%$ of the constrained variability, respectively. The $\mathrm{pH}$ and DOC in soil solution were the main contributors to F1 and both were negatively correlated $\left(R=-0.92, R^{2}=0.85\right)$. The $\mathrm{Ag}$ flux and $\mathrm{Ag}$ in soil solution were the main contributors to F2. The contribution of the plant mass was low on both axes.

A permutation test revealed a highly significant linear relationship between the response variables and the explanatory environmental variables ( $p$-value $<0.0001)$. The $\mathrm{Ag}$ flux was positively and strongly correlated with the exposure concentration of $\mathrm{Ag}\left(R=0.97, R^{2}=0.95\right)$, negatively and strongly correlated with soil clay content $\left(R=-0.84, R^{2}=0.88\right)$ and CEC $(R$ $\left.=-0.91, R^{2}=0.84\right)$, moderately correlated with the DOC $(R=$ $\left.-0.49, R^{2}=0.24\right)$ and carbonate concentration $\left(R=0.43, R^{2}=\right.$ 0.20 ), and poorly correlated with the soil organic matter content $\left(R^{2}=0.05\right)$ and $\mathrm{pH}\left(R^{2}=0.01\right)$. The concentration of silver

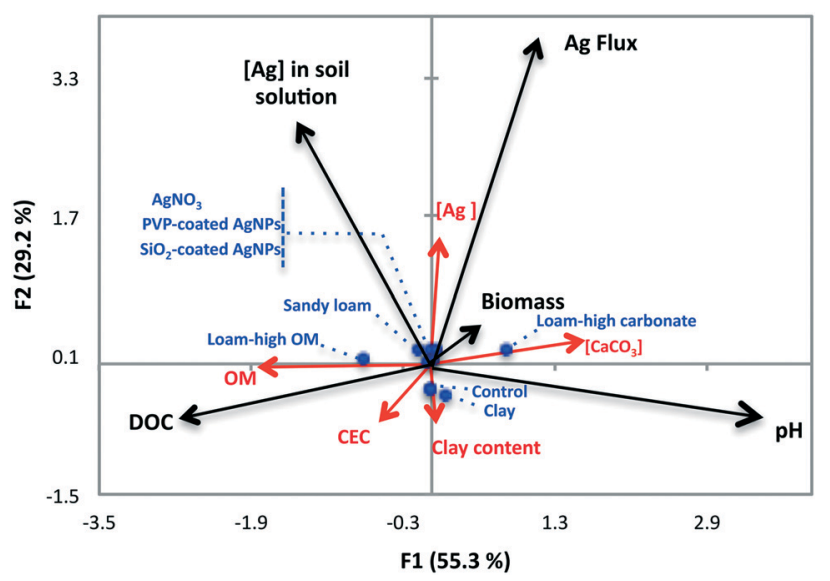

Fig. 3 Redundancy analysis (RDA) ordination biplot showing the relationships between the response variables (black arrows) and the explanatory quantitative (red arrows) and non-quantitative environmental variables (centroids shown as blue circles). in the soil solution was best correlated with the clay content $\left(R=0.91, R^{2}=0.84\right)$ and the exposure concentration of $\mathrm{Ag}(R=$ $\left.0.86, R^{2}=0.74\right)$ and poorly correlated with the other environmental variables $\left(R^{2} \leq 0.35\right)$. The right-angled projections of the centroids for the Ag treatment variable set up a gradient along the Ag flux variable, with a negative contribution for controls (no Ag added), whereas in the other treatments, $\mathrm{AgNO}_{3}, \mathrm{SiO}_{2}$ - and PVP-AgNPs, the contributions were positive. This highlights the fact that the trends in the Ag flux were similar under the $\mathrm{SiO}_{2}$-AgNP, PVP-AgNP, and $\mathrm{AgNO}_{3}$ treatments. The right-angled projections of the centroids of the soil variable on the $\mathrm{Ag}$ flux made some soils stand out: the clay soil that contributed negatively to the Ag flux and the loam with high carbonate content that contributed positively. The same analysis of the concentration of silver in soil solution variable emphasized the positive contribution of loam with high OM content, and the clay and loam with high carbonate content with similar but negative contributions.

The general trend showed the clay soil to have the lowest $\mathrm{Ag}$ concentration in the soil solution and the lowest $\mathrm{Ag}$ flux, the loam with the high carbonate content to have the lowest concentration of $\mathrm{Ag}$ in soil solution but the highest $\mathrm{Ag}$ flux, and the loam with high OM content to have a high concentration of $\mathrm{Ag}$ in soil solution but a low Ag flux. The sandy soil contributed poorly to these two variables. These relationships are discussed in more detail in the following sections.

\section{$\mathrm{Ag}$ phytoavailability from $\mathrm{AgNPs}$ and $\mathrm{AgNO}_{3}$ at PEC is} indistinguishable from that of geogenic silver.

In the literature, the lowest Ag concentration used in soilplant transfer was $0.5 \mathrm{mg} \mathrm{kg}{ }^{-1}$ in a sand matrix. ${ }^{33}$ Here, we used the RHIZOtest as a bioassay to detect differences in Ag phytoavailability between treatments within the range of AgNP PEC in agricultural soils. ${ }^{7}$ Fig. 4 shows the relationship between the silver flux as a function of soil type and modalities. A modality is defined here as a silver treatment at a given exposure concentration. For the lowest concentration tested $\left(0.0015 \mathrm{mg} \mathrm{kg}^{-1}\right)$, the $\mathrm{Ag}$ flux induced by $\mathrm{AgNPs}\left(\mathrm{SiO}_{2}\right.$ or PVP-coated) or $\mathrm{AgNO}_{3}$ did not significantly differ ( $p$-value $>0.05$ ) from the controls (no Ag added).

While the RHIZOtest was unable to detect differences with controls in Ag phytoavailability at $0.0015 \mathrm{mg} \mathrm{kg}^{-1}$, it was sufficiently sensitive to detect a soil-dependent $\mathrm{Ag}$ flux at 0.15 $\mathrm{mg} \mathrm{kg}{ }^{-1}$. Fig. 4 shows that for 7 out of 12 of the modalities, the $\mathrm{Ag}$ fluxes in fescue exposed to $0.15 \mathrm{mg} \mathrm{kg}^{-1}$ of silver, as $\mathrm{AgNO}_{3}$ or $\mathrm{AgNPs}\left(\mathrm{SiO}_{2}-\right.$ or PVP-coated), were significantly higher than those in the control groups. The Ag fluxes in fescue exposed to the clay and the loam soils with high carbonate content differed from those in the controls, regardless of the Ag treatment. In contrast, the Ag flux in fescues exposed to the loam soil with high OM content or the sandy soils did not significantly differ from those in the controls, except for the $\mathrm{AgNO}_{3}$ treatment in the loam soil with high OM content.

This result highlights the sensitivity of the RHIZOtest as a bioassay to detect differences in phytoavailability in soils 


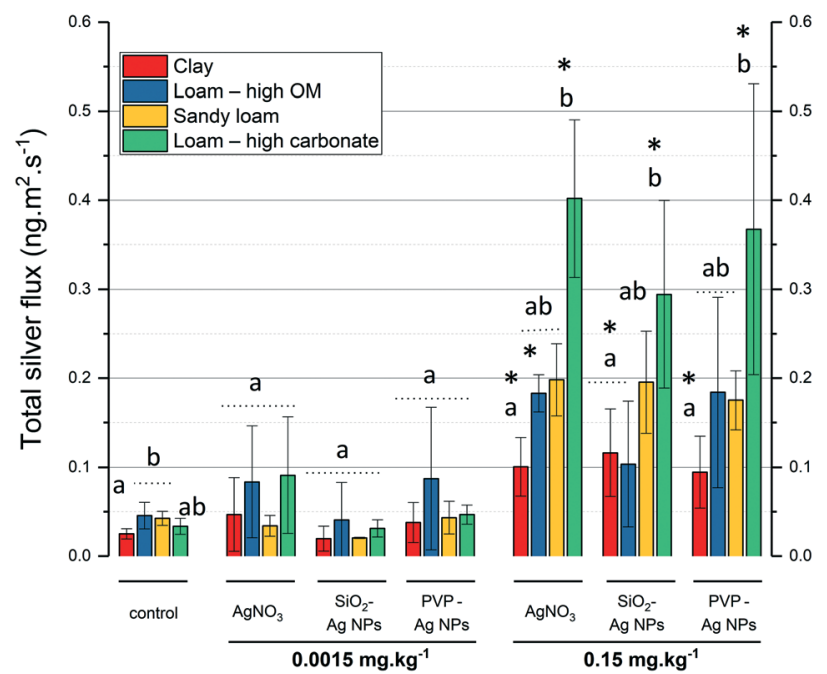

Fig. 4 Total silver flux ( $\mathrm{ng} \mathrm{m} \mathrm{m}^{-2} \mathrm{~s}^{-1}$ ) obtained in fescue cultivated on four soils ( $n=3$ to $5, \pm S D$ ). A modality is defined here as a silver treatment at a given exposure concentration. Different letters represent significant differences (Kruskal-Wallis test) between soils for each modality. * represents significant differences (Kruskal-Wallis test) compared to the control.

with contrasting properties, even at a Ag exposure concentration lower than the concentrations already published $(0.15$ $\mathrm{mg} \mathrm{kg}{ }^{-1}$ in this study versus $0.5 \mathrm{mg} \mathrm{kg}^{-1}$ (ref. 33)). The sensitivity of the RHIZOtest has already been highlighted with $\mathrm{CeO}_{2}$ NMs. $^{16}$

\section{Antagonist clay and carbonate effects on $\mathrm{Ag}$ phytoavailability} at $100 \times$ PEC

Fig. 4 shows that for a given modality, Ag fluxes always increased in the order clay $<$ loam with high OM content $<$ sandy loam < loam with high carbonate content (Ag fluxes being significantly lower in the clay soil than in the loam soil with high carbonate content). Fig. 5 shows the Ag concentration in soil solution plotted as a function of the exposure concentration and also highlights a repetitive pattern for a given modality. Significantly lower Ag concentrations in soil solutions were measured in the clay soil and loam soil with high carbonate content than in the sandy soil and loam soil with high OM content. The Ag concentrations in soil solutions were always not statistically different $(p$-value $\geq 0.05)$ in the clay soil and loam soil with high carbonate content, while the Ag fluxes were lower in the clay soil.

The clay and loam soils with high carbonate content mainly differed in their clay content, CEC, and carbonate content (Fig. 2). It is noteworthy that CEC and clay content are related since CEC arises from various negative charges on soil particle surfaces, especially those of clay minerals and soil organic matter. Together with the RDA (Fig. 3), the results presented in Fig. 4 and 5 show that (i) interactions between $\mathrm{Ag}$ and clay minerals hindered the $\mathrm{Ag}$ flux, and (ii) suggest a potential role for carbonates in $\mathrm{Ag}$ phytoavailability in the soil. Several studies already highlighted the major role of

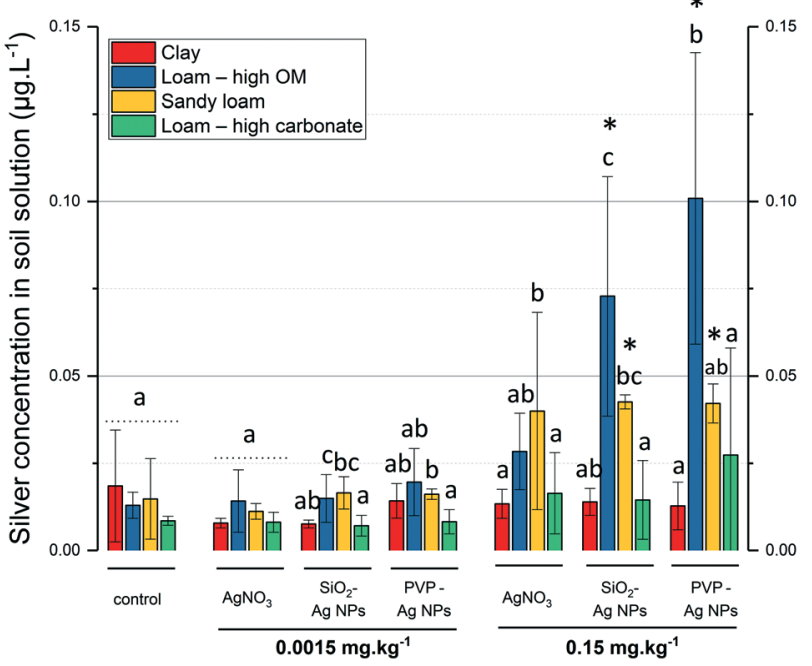

Fig. 5 Total silver concentration in soil solution $\left(\mu \mathrm{g} \mathrm{L}^{-1}\right)$ in the four soils $(n=5, \pm$ SD). A modality is defined here as a silver treatment at a given exposure concentration. Different letters represent significant differences (Kruskal-Wallis test) between soils in each modality. * represents significant differences (Kruskal-Wallis test) compared to the control.

the physical-chemical properties of the soil in the mobility and transformation of Ag NPs in natural soils. Using three soils with property gradients (pH 4.6 to 8 , clay content $12 \%$ to $27 \%$, CEC 8.5 to $15 \mathrm{cmol} \mathrm{kg}^{-1}$, and organic matter content 0.66 to $2.5 \%$ ), Wang et al. $(2015)^{34}$ correlated the mobility of PVP-AgNPs positively with $\mathrm{pH}, \mathrm{CEC}$, and organic matter content. Cornelis et al. $(2012)^{35}$ used a larger set of 16 natural soils with a broader range of chemical and physical properties ( $\mathrm{pH} 4$ to 7.58 , clay content 1 to 59\%, CEC 0.2 to 65.7 $\mathrm{cmol} \mathrm{kg}^{-1}$, and carbon content 0.9 to $7 \%$ ). These authors correlated the partitioning of $\mathrm{Ag}$ with the soil clay content and suggested the preferential adsorption of the negatively charged citrate-coated AgNPs on the positively-charged surface sites of clay-sized minerals. Recently, Zhou et al. $(2017)^{36}$ demonstrated that negatively-charged AgNPs do not alter the stability of montmorillonite clay at $\mathrm{pH} 8$, but interact with the edges of clays and coagulate at $\mathrm{pH} 4$. At the apex of the plant roots, exudation of protons and organic acids usually locally decreases the $\mathrm{pH}$ to close to 4.5 to enable the uptake of nutrients. This suggests that even if clays do not interact with $\mathrm{Ag}$ at the $\mathrm{pH}$ of the clay soil (pH 7.45) and loam soil with high carbonate content ( $\mathrm{pH}$ 7.97), they could locally favor $\mathrm{Ag}$ immobilization in the vicinity of the root apex due to the plant exudation and the decrease in $\mathrm{pH}$.

In the loam soil with high carbonate content (with low clay content), the formation of $\mathrm{Ag}_{2} \mathrm{CO}_{3}$ could account for the low $\mathrm{Ag}$ concentration in the soil solution observed at $0.15 \mathrm{mg}$ $\mathrm{kg}^{-1}$ of $\mathrm{AgNO}_{3}, \mathrm{PVP}-$ and $\mathrm{SiO}_{2}$-AgNPs. Sekine et al. $(2014)^{37}$ studied carbonate- $\mathrm{Ag}$ interactions in neutral $(\mathrm{pH}$ 6.9) and alkaline soils ( $\mathrm{pH}$ 7.8). $\mathrm{Ag}_{2} \mathrm{CO}_{3}$ was only detected in the soils freshly spiked with $\mathrm{AgNO}_{3}$ followed by its disappearance after three months of incubation. In the loam soil with high carbonate content, $\mathrm{Ag}_{2} \mathrm{CO}_{3}$ species are likely to precipitate $\left(K_{\mathrm{sp}}=\right.$ 


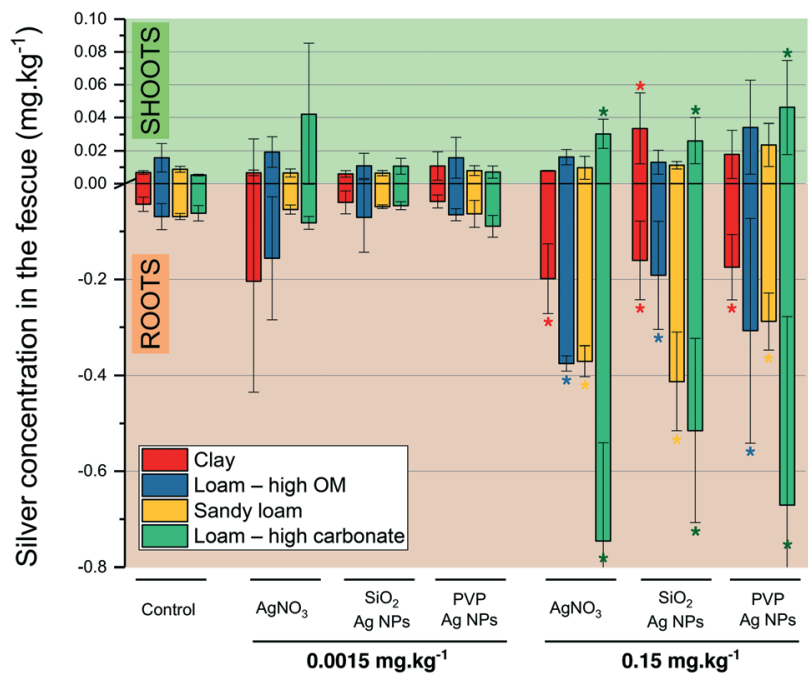

Fig. 6 Silver concentration in fescue leaves and roots $\left(\mathrm{mg} \mathrm{kg}^{-1}\right)$ on the four soils $(n=5, \pm \mathrm{SD})$. * represents significant differences (KruskalWallis test) compared to the control.

$8.5 \times 10^{-12}$ ) as already observed by XAS. ${ }^{37}$ Several studies have highlighted the ability of plants to change the $\mathrm{pH}$ of their rhizosphere. For instance, the roots of tomato and rape were shown to cause systematic acidification of calcareous soil. ${ }^{38}$ Therefore, a decrease in $\mathrm{pH}$ in the vicinity of the root apex in the loam soil with high carbonate content could favor the dissolution of $\mathrm{Ag}_{2} \mathrm{CO}_{3}$ over time and hence influence $\mathrm{Ag}$ phytoavailability. This root-induced change in $\mathrm{pH}$ could explain the high fluxes observed in fescue in the loam soil with high carbonate content despite the low concentration of $\mathrm{Ag}$ in the soil solution.

$\mathrm{Ag}$ from $\mathrm{AgNO}_{3}$ and $\mathrm{Ag}$ NPs is similarly phytoavailable and translocated at 100 $\times$ PEC

Fig. 6 reports the silver concentrations in the roots and shoots of fescue exposed to AgNPs and $\mathrm{AgNO}_{3}$ at PEC and 100 $\times$ PEC, in the different soils. PERMANOVA revealed a significant impact of the Ag exposure concentration $(F=13.1$, $p$-value $<0.0001)$, soil type $(F=4.1, p$-value $<0.01)$, and treatment $(F=3.3, p$-value $<0.01)$ on the Ag concentration in the shoots. Interestingly, no linear correlation was found between the silver concentration in the shoots and in the roots $\left(R=0.32, R^{2}=0.09\right)$.

The silver concentrations in the roots mainly mirrored the trend observed in Ag flux discussed in the previous sections. At PEC, the Ag concentration in the fescue shoots and roots following exposure to AgNPs $\left(\mathrm{SiO}_{2}\right.$ - or PVP-coated) or $\mathrm{AgNO}_{3}$ did not significantly differ $(p$-value $>0.05)$ from the controls (no Ag added). However, at $100 \times$ PEC, in 4 out of 12 modalities, the concentrations of $\mathrm{Ag}$ in shoots were significantly higher than those of the respective controls, as in the loam soil with high carbonate content for both Ag NPs (PVP- and $\mathrm{SiO}_{2}$-AgNPs) and $\mathrm{AgNO}_{3}$ and in the clay soil for $\mathrm{SiO}_{2}$-AgNPs. This confirms the previous conclusion that soil parameters prevail over the form of silver (nanoparticulate or dissolved), in Ag phytoavailability and translocation to plant shoots.

At 100× PEC, neither the nanoparticulate (irrespective of the organic or inorganic coating) nor the ionic form modified the flux of $\mathrm{Ag}$ in fescue (Fig. 4). The behavior of Ag NPs in soil pore water (dissolution, complexation and aggregation) was investigated $^{39}$ and the coating (citrate vs. PVP) was shown to strongly affect the physical-chemical behavior of Ag NPs in terms of the aggregation state and partitioning to pore water. Here, we found that regardless of the coating (organic $v s$. inorganic) and the form (nanoparticulate vs. ionic) at 100 $\times$ PEC, the Ag flux was not impacted. The RHIZOtest outputs should be however considered as an evaluation of the phytoavailability measured under standardized conditions, which consequently do not per se take into account some important processes in comparison with field experiments (e.g. chronic exposure to contaminants, plant life cycle, etc.).

\section{Conflicts of interest}

The authors have no conflicts to declare.

\section{Acknowledgements}

The authors are grateful to the French Environment and Energy Management Agency (ADEME) and Labex SERENADE for Clément Layet's PhD grant. The project leading to this publication received funding from the Excellence Initiative of AixMarseille University - A*MIDEX, a French "Investissements d'Avenir" program, through its associated Labex SERENADE project. The authors acknowledge INSU (CNRS) for funding the study via the EC2CO-ECODYN call. The authors acknowledge the CNRS funding for the GDRi iCEINT, and the OSUInstitut Pythéas. We also thank X. Lacan and C. Villefranque from RAGT semences who kindly provided the tall fescue seeds and the European Synchrotron Radiation Facility for access to the synchrotron radiation facilities.

\section{Notes and references}

1 M. E. Vance, T. Kuiken, E. P. Vejerano, S. P. McGinnis, M. F. Hochella, Jr., D. Rejeski and M. S. Hull, Nanotechnology in the real world: Redeveloping the nanomaterial consumer products inventory, Beilstein J. Nanotechnol., 2015, 6, 1769-1780.

2 J. Pulit-Prociak and M. Banach, Silver nanoparticles - a material of the future...?, Open Chem., 2016, 14, 76.

3 C.-N. Lok, C.-M. Ho, R. Chen, Q.-Y. He, W.-Y. Yu, H. Sun, P. K.-H. Tam, J.-F. Chiu and C.-M. Che, Proteomic Analysis of the Mode of Antibacterial Action of Silver Nanoparticles, J. Proteome Res., 2006, 5, 916-924.

4 F. Gottschalk, C. Lassen, J. Kjoelholt, F. Christensen and B. Nowack, Modeling Flows and Concentrations of Nine Engineered Nanomaterials in the Danish Environment, Int. J. Environ. Res. Public Health, 2015, 12, 5581-5602.

5 M. Kah and T. Hofmann, Nanopesticide research: Current trends and future priorities, Environ. Int., 2014, 63, 224-235. 
6 C. Meier, A. Voegelin, A. Pradas del Real, G. Sarret, C. R. Mueller and R. Kaegi, Transformation of Silver Nanoparticles in Sewage Sludge during Incineration, Environ. Sci. Technol., 2016, 50, 3503-3510.

7 T. Y. Sun, F. Gottschalk, K. Hungerbuehler and B. Nowack, Comprehensive probabilistic modelling of environmental emissions of engineered nanomaterials, Environ. Pollut., 2014, 185, 69-76.

8 C. Levard, E. M. Hotze, G. V. Lowry and G. E. Brown, Environmental Transformations of Silver Nanoparticles: Impact on Stability and Toxicity, Environ. Sci. Technol., 2012, 46, 6900-6914.

9 A. Cox, P. Venkatachalam, S. Sahi and N. Sharma, Silver and titanium dioxide nanoparticle toxicity in plants: A review of current research, Plant Physiol. Biochem., 2016, 107, 147-163.

10 X. Ma, J. Geiser-Lee, Y. Deng and A. Kolmakov, Interactions between engineered nanoparticles (ENPs) and plants: Phytotoxicity, uptake and accumulation, Sci. Total Environ., 2010, 408, 3053-3061.

11 J. Wang, Y. Koo, A. Alexander, Y. Yang, S. Westerhof, Q. Zhang, J. L. Schnoor, V. L. Colvin, J. Braam and P. J. J. Alvarez, Phytostimulation of Poplars and Arabidopsis Exposed to Silver Nanoparticles and $\mathrm{Ag}+$ at Sublethal Concentrations, Environ. Sci. Technol., 2013, 47, 5442-5449.

12 P. Wang, E. Lombi, S. K. Sun, K. G. Scheckel, A. Malysheva, B. A. McKenna, N. W. Menzies, F. J. Zhao and P. M. Kopittke, Characterizing the uptake, accumulation and toxicity of silver sulfide nanoparticles in plants, Environ. Sci.: Nano, 2017, 4, 448-460.

13 J. P. Stegemeier, F. Schwab, B. P. Colman, S. M. Webb, M. Newville, A. Lanzirotti, C. Winkler, M. R. Wiesner and G. V. Lowry, Speciation Matters: Bioavailability of Silver and Silver Sulfide Nanoparticles to Alfalfa (Medicago sativa), Environ. Sci. Technol., 2015, 49, 8451-8460.

14 A. E. Pradas del Real, V. Vidal, M. Carrière, H. CastilloMichel, C. Levard, P. Chaurand and G. Sarret, Silver Nanoparticles and Wheat Roots: A Complex Interplay, Environ. Sci. Technol., 2017, 51, 5774-5782.

15 N. T. Basta, J. A. Ryan and R. L. Chaney, Trace Element Chemistry in Residual-Treated Soil, J. Environ. Qual., 2005, 34, 49-63.

16 C. Layet, M. Auffan, C. Santaella, C. Chevassus-Rosset, M. Montes, P. Ortet, M. Barakat, B. Collin, S. Legros, M. N. Bravin, B. Angeletti, I. Kieffer, O. Proux, J.-L. Hazemann and E. Doelsch, Evidence that Soil Properties and Organic Coating Drive the Phytoavailability of Cerium Oxide Nanoparticles, Environ. Sci. Technol., 2017, 51, 9756-9764.

17 W.-M. Lee, J. I. Kwak and Y.-J. An, Effect of silver nanoparticles in crop plants Phaseolus radiatus and Sorghum bicolor: Media effect on phytotoxicity, Chemosphere, 2012, 86, 491-499.

18 C. O. Dimkpa, D. E. Latta, J. E. McLean, D. W. Britt, M. I. Boyanov and A. J. Anderson, Fate of $\mathrm{CuO}$ and $\mathrm{ZnO}$ Nanoand Microparticles in the Plant Environment, Environ. Sci. Technol., 2013, 47(9), 4734-4742.
19 A. E. Pradas del Real, H. Castillo-Michel, R. Kaegi, B. Sinnet, V. Magnin, N. Findling, J. Villanova, M. Carrière, C. Santaella, A. Fernández-Martínez, C. Levard and G. Sarret, Fate of Ag-NPs in Sewage Sludge after Application on Agricultural Soils, Environ. Sci. Technol., 2016, 50, 1759-1768.

20 C. L. Doolette, M. J. McLaughlin, J. K. Kirby and D. A. Navarro, Bioavailability of silver and silver sulfide nanoparticles to lettuce (Lactuca sativa): Effect of agricultural amendments on plant uptake, J. Hazard. Mater., 2015, 300, 788-795.

21 K. Schlich, M. Hoppe, M. Kraas, E. Fries and K. Hund-Rinke, Ecotoxicity and fate of a silver nanomaterial in an outdoor lysimeter study, Ecotoxicology, 2017, 26, 738-751.

22 R. Benoit, K. J. Wilkinson and S. Sauvé, Partitioning of silver and chemical speciation of free $\mathrm{Ag}$ in soils amended with nanoparticles, Chem. Cent. J., 2013, 7, 75.

23 G. Cornelis, L. Pang, C. Doolette, J. K. Kirby and M. J. McLaughlin, Transport of silver nanoparticles in saturated columns of natural soils, Sci. Total Environ., 2013, 463-464, 120-130.

24 ISO-16198, Soil quality - Plant-based test to assess the environmental bioavailability of trace elements to plants, 2015.

25 S. Ahlberg, A. Antonopulos, J. Diendorf, R. Dringen, M. Epple, R. Flöck, W. Goedecke, C. Graf, N. Haberl, J. Helmlinger, F. Herzog, F. Heuer, S. Hirn, C. Johannes, S. Kittler, M. Köller, K. Korn, W. G. Kreyling, F. Krombach, J. Lademann, K. Loza, E. M. Luther, M. Malissek, M. C. Meinke, D. Nordmeyer, A. Pailliart, J. Raabe, F. Rancan, B. Rothen-Rutishauser, E. Rühl, C. Schleh, A. Seibel, C. Sengstock, L. Treuel, A. Vogt, K. Weber and R. Zellner, PVPcoated, negatively charged silver nanoparticles: A multicenter study of their physicochemical characteristics, cell culture and in vivo experiments, Beilstein J. Nanotechnol., 2014, 5, 1944-1965.

26 M. Kosmulski, A literature survey of the differences between the reported isoelectric points and their discussion, Colloids Surf., A, 2003, 222, 113-118.

27 M. Ringner, What is principal component analysis?, Nat. Biotechnol., 2008, 26, 303-304.

28 C. R. Team, Team RDC.R: A Language And Environment For Statistical Computing, $\mathrm{R}$ Foundation for Statistical Computing, Vienna, Austria, 2012.

29 S. Dray, A. B. Dufour and D. Chessel, The ade4 package - II: Two-table and K-table methods, $R$ News, 2007, vol. 7, pp. 4752.

30 S. Dray, A.-B. Dufour and J. Thioulouse, Analysis of Ecological Data : Exploratory and Euclidean Methods in Environmental Sciences, $R$ package, 2017, Version 1.7-6.

31 J. F. Oksanen, G. Blanchet, M. Friendly, R. Kindt, P. Legendre, D. McGlinn, P. R. Minchin, R. B. O'Hara, G. L. Simpson, P. Solymos, M. H. S. Henry, E. Szoecs and H. Wagner, vegan: Community Ecology Package, R package, 2013, Version 2.4-3.

32 Y. Benjamini and Y. Hochberg, Controlling the false discovery rate: A practical and powerful approach to multiple testing, J. R. Stat. Soc. Series B Stat. Methodol., 1995, 57, 289-300. 
33 C. O. Dimkpa, A. Calder, P. Gajjar, S. Merugu, W. Huang, D. W. Britt, J. E. McLean, W. P. Johnson and A. J. Anderson, Interaction of silver nanoparticles with an environmentally beneficial bacterium, Pseudomonas chlororaphis, J. Hazard. Mater., 2011, 188, 428-435.

34 D. Wang, D. P. Jaisi, J. Yan, Y. Jin and D. Zhou, Transport and Retention of Polyvinylpyrrolidone-Coated Silver Nanoparticles in Natural Soils, Vadose Zone J., 2015, 14, DOI: 10.2136/vzj2015.01.0007.

35 G. Cornelis, C. Doolette, M. Thomas, M. J. McLaughlin, J. K. Kirby, D. G. Beak and D. Chittleborough, Retention and Dissolution of Engineered Silver Nanoparticles in Natural Soils, Soil Sci. Soc. Am. J., 2012, 76, 891-902.

36 D. Zhou, A. I. Abdel-Fattah and A. A. Keller, Clay Particles Destabilize Engineered Nanoparticles in Aqueous Environments, Environ. Sci. Technol., 2012, 46, 7520-7526.
37 R. Sekine, G. Brunetti, E. Donner, M. Khaksar, K. Vasilev, Å. K. Jämting, K. G. Scheckel, P. Kappen, H. Zhang and E. Lombi, Speciation and Lability of Ag-, AgCl-, and Ag2SNanoparticles in Soil Determined by X-ray Absorption Spectroscopy and Diffusive Gradients in Thin Films, Environ. Sci. Technol., 2014, 49, 897-905.

38 V. Chaignon, F. Bedin and P. Hinsinger, Copper bioavailability and rhizosphere $\mathrm{pH}$ changes as affected by nitrogen supply for tomato and oilseed rape cropped on an acidic and a calcareous soil, Plant Soil, 2002, 243, 219-228.

39 A. R. Whitley, C. Levard, E. Oostveen, P. M. Bertsch, C. J. Matocha, F. von der Kammer and J. M. Unrine, Behavior of $\mathrm{Ag}$ nanoparticles in soil: Effects of particle surface coating, aging and sewage sludge amendment, Environ. Pollut, 2013, 182, 141-149. 